\title{
DIREITO PENAL DO INIMIGO: UMA MUDANÇA PARADIGMÁTICA DO DIREITO PENAL
}

\author{
CRIMINAL LAW OF THE ENEMY: A PARADIGMATIC CHANGE IN CRIMINAL LAW \\ BERNADETE LIMA DOMINGUES ${ }^{2}$ \\ bernadetedomingues@yahoo.com.br
}

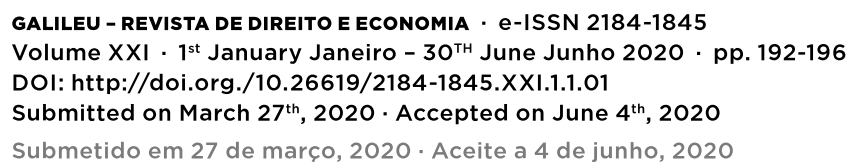

RESUMO Percebe-se, no mundo contemporâneo, um claro desequilíbrio do Direito penal que deve ser entendido como ultima et extrema ratio e não como prima solo et unica ratio. Impõe-se uma convergência das atuais linhas de pensamento científico, para fins de afirmação do ser humano como ser de liberdade e como ser de responsabilidade, consubstanciado no Direito penal do ser humano.

PALAVRAS-CHAVE Direito penal do inimigo - Direito penal garantista - liberdade e responsabilidade - dignidade humana.

ABSTRACT In the contemporary world, there is a clear imbalance in criminal law, which should be understood as an ultima et extrema ratio and not as a prima, solo et unica ratio. A convergence of the current lines of scientific thought is necessary, for the purpose of affirming the human being as a being of freedom and as a being of responsibility, embodied in the criminal law of the human being.

KEYworDS Enemy's criminal law Guarantee criminal law - freedom and responsibility - human dignity.

As mudanças paradigmáticas do Direito penal, na modernidade, vêm sendo objeto de debates nomeadamente na comunidade jurídico-criminal, onde se destacam duas linhas de pensamento divergentes, consistentes naqueles que defendem um Direito penal humanista e naqueles que defendem um Direito penal securitário ou policializado. Há um claro desequilíbrio do Direito penal, porquanto o princípio da subsidiariedade cede lugar ao princípio prima solo et unica ratio, concretizado no denominado Direito

1 Este artigo corresponde a um dos comentários científico da Unidade Curricular de Doutoramento em Direito - Direito: da norma ao procedimento e à fase aplicativa -, lecionada pelo Professor Doutor Manuel Monteiro Guedes Valente.

2 Doutoranda em Direito da Universidade Autónoma de Lisboa. 
Penal do inimigo, em consenso com a teoria de Günther Jakobs ${ }^{3}$. Essa teoria é rejeitada por penalistas humanistas, a exemplo de Manuel Monteiro Guedes Valente ${ }^{4}$, cuja obra fundamenta a presente reflexão. Igualmente, neste breve apontamento, traz-se a lume a concepção sistêmica-funcional de Niklas Luhmann, exposta por António Manuel de Almeida Costa ${ }^{5}$, em obra de valor contributivo para o pensar científico, acerca dos conteúdos normativos de opções ideológico-políticas. A tese de Günter Jakobs tem na de Niklas Luhmann seu ponto de partida, sendo ambas representativas do regresso ao positivismo jurídico, de pensamento racional, onde conceitos como dignidade humana se despem de autonomia. O "balanço literário", de Günter Grass ${ }^{6}$, obra também em referência, conta-nos sobre os reflexos de Auschwitz na literatura, e nos traz à lembrança o alcance do autoritarismo, da racionalidade e do desprezo para com a dignidade humana.

A crítica elaborada à teoria de Günther Jakobs, tecida por Manuel Monteiro Guedes Valente $^{7}$, é um alerta sobre a transformação que as bases do Direito Penal têm sofrido, sobre a resistência que se deve impor ao autoritarismo penal, em face da caracterização do delinquente que se torna o "inimigo" da sociedade e do Estado. O que ocorre é um verdadeiro ataque às normas penais e processuais, de constitucionalidade duvidosa. É que, sob o pálio da segurança pública, está-se a ver uma inversão do Direito Penal garantista, postulado desde o iluminismo penal de Cesare Beccaria $^{8}$, cujas bases estão assentadas nos princípios do Estado de Direito Democrático ${ }^{9}$, nos valores e garantias humanistas, na liberdade e na dignidade da pessoa humana ${ }^{10}$.

3 Günther Jakobs (nascido em 1937) é apontado como o atual teorizador do Direito penal do inimigo, cujas bases filosóficas residem na guerra ao terror, ao terrorista, ao traficante de armas, de drogas, de seres e de órgãos humanos, ao crime organizado, de entre outros. Para um estudo aprofundado do tema, JAKOBS, Günther e CANCIO MELIÁ, Manuel - Derecho Penal del Enemigo. Tradução do alemão Bürgerstrafrecht und Feindstrafrecht de Manuel Cancio Meliá. 2. ${ }^{a}$ Edição. Madrid: Thomson-Civitas, 2003. Quanto a uma análise crítica, VALENTE,

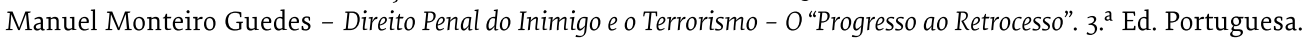
Coimbra: Almedina, 2019, p. 50.

4 VALENTE, Manuel Monteiro Guedes - Direito Penal do Inimigo .... $3 .^{\text {a }}$ Ed. Portuguesa, p. 11.

5 COSTA, António Manuel de Almeida - O Funcionalismo Sistémico de N. Luhmann e os seus Reflexos no Universo Jurídico. Coimbra: Almedina, 2018.

6 GRASS, Günter - Escrever Depois de Auschwitz. 2. ${ }^{\text {a }}$ Ed. Português. Alfragide: Dom Quixote. 2008. ISBN 978-972-203651-1.

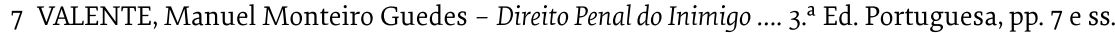

8 BeCCARIA, CESARE - Dos Delitos e das Penas. Tradução do italiano Dei Delittie delle Pene de José de Faria Costa. Lisboa: Fundação Calouste Gulbenkian, 1998. Quanto a uma análise da dimensão iluminista em Cesare Beccaria, RAMOS, Calebe Brito; OLIVEIRA DE SOUZA, Rodrigo Lobato e ESTRELA, Thiago Aires - «Direito Penal do Inimigo: para além da Constitucionalidade do Direito Penal (?)».In: Manuel Monteiro Guedes VALENTE (Coord.). Os Desafios do Direito (Penal) do Século XXI. Lisboa: Legit Edições, 2018, pp.121-144.

9 Sobre o sentido constitucional do "Estado de Direito Democrático, ver OTERO, Paulo - Direito Constitucional Português. Vol I: Identidade Constitucional. Almedina: Lisboa, 2017, pp. 51-53.

10 A República Portuguesa é baseada na dignidade da pessoa humana, na forma consagrada pelo artigo $1 .{ }^{\circ}$ da CONSTITUIÇÃO da República Portuguesa. 
Nesse contexto, impende analisar a teoria sistémica-funcional formulada por Niklas Luhmann, cujos traçados fundamentais e suas implicações no universo jurídico, evidenciados por António Manuel de Almeida Costa ${ }^{11}$, demonstram como essa corrente funcionalista sustentada por Günther Jakobs, em que o juízo de antijuridicidade recai sobre o autor, e a culpabilidade cede lugar à perigosidade e à previsibilidade de sua conduta, faz com que o Direito penal tenha como função a proteção de suas próprias normas. Em face disso, há de se perguntar se a teoria sistêmica luhmanniana se aplica ao Direito Penal, se o Direito se comporta como um sistema autopoiético $^{12}$ ou autorreferencial. A conclusão é pela negativa de aplicação da teoria, porquanto a "neutralidade axiológica e ideológico-política"13 e a funcionalização da pessoa que desveste o homem de sua individualidade permitem a indiferença ao autoritarismo e, consequentemente, permitem que a confecção de normas penais fiquem ao sabor de decisão política do legislador, sem que haja, no organismo social, instâncias de críticas a esse positivismo. Portanto, o Direito Penal, que sabidamente sofre influências políticas e econômicas, não pode ser entendido como um sistema fechado, pois sua função garantista está, dentre outras, em restringir o âmbito de incidência de imposições penais despropositadas, injustas e antidemocráticas.

Tem-se que a função essencial do Direito penal é a de limitar o poder soberano de punir e o excesso de ação punitiva estatal. Entretanto, a percepção de risco e da "sociedade de risco"14, nos tempos atuais, tem levado a uma hipertrofia legislativa e vulgarização das normas penais, ao aparecimento de tipos penais de perigo abstrato que prescindem da ocorrência de dano material efetivo, a um recrudescimento da criminalização, com incidência de penas que justificam a prevenção geral positiva e o controle social. O delinquente passa a ser visto como um inimigo da sociedade, não como um Ser Humano que deve ser tratado dignamente, mas como uma coisa, uma não-pessoa, em total discordância com os direitos e garantias fundamentais do cidadão. O Direito penal é a ultima et extrema ratio e, como tal, a ele se aplica o princípio da subsidiariedade, e não o da prima solo et unica

11 COSTA, António Manuel de Almeida - O Funcionalismo Sistémico de N. Luhmann ..., pp. 42 e ss.

12 Niklas Luhmann desenvolveu a teoria dos sistemas, sob o conceito de autopoiese, ao argumento de que a comunicação é a base operacional de uma sociedade (funcionalismo sistémico). O autor compreende o Direito como um sistema autopoiético. Autopoiesis é um termo grego adaptado à sociologia, por Luhmann, inspirado em dois biólogos chilenos, Umberto Maturana e Francisco Varela, conforme esclarece HESPANHA, António Manuel - O Caleidoscópio do Direito - O Direito e a Justiça nos dias e no mundo de hoje. 2. ${ }^{\text {a }}$ ed. Coimbra: Almedina, 2019, p. 216.

13 COSTA, António Manuel de Almeida - O Funcionalismo Sistémico de N. Luhmann ..., p. 76.

14 Nessa obra clássica da Sociologia, o autor chama a atenção para a percepção que se tem do mundo atual, das sociedades, percepção essa moldada pelos perigos e riscos que nos cercam, tanto os naturais como os gerados pelo próprio homem, a exemplo das alterações ambientais e climáticas, do terrorismo, das crises financeiras, dos crimes transnacionais, que nos fazem buscar a segurança a qualquer preço, mesmo que em detrimento das liberdades. BECK, Ulrich - Sociedade de risco mundial - em busca da segurança perdida. Lisboa: Edições 70, 2016. pp. 22-56. 
ratio, como está a se ver. A percepção é que a imperiosidade de se combater outros crimes e organizações criminosas, nomeadamente o terrorismo, o tráfico de pessoas, de drogas e de armas, homicídios e roubos qualificados, levou o legislador a violar nomeadamente o princípio da subsidiariedade, e a conceder uma tal envergadura ao Direito penal, a ponto de elevá-lo à condição de única solução de combate ao crime.

O que deveria ser tratado tão somente no plano ou dimensão do ser (a exemplo, ser negro, ser homossexual, ser judeu ou mulçumano, ser pobre etc.), passou a ser dimensionado no âmbito do dever-ser, em que o Direito penal passou a centralizar-se no autor e não no facto. A ameaça de terrorismo é apontada como uma das causas da demanda excessiva por segurança e consequentemente por legislação descomedida, dando lugar a uma intervenção penal mais adequada à guerra (jus bélico) e à prevenção policial ${ }^{15}$ (mesmo diante da prática de atos preparatórios), do que à retribuição ética da ofensa ao bem jurídico lesado.

A política criminal ${ }^{16}$ não pode ter como objetivo a guerra ao terror, disseminando mais terror, sob pena de se proceder a um ver- dadeiro retrocesso jurídico e sócio-político. Esse problema não pode ser subtraído à reflexão, não pode ser olvidado pelos operadores do Direito.

O regime ditatorial de Hitler cometeu os maiores excessos, fomentou a raiva e o ódio contra os judeus, personificou a sanha punitiva do Estado, por meio da concretização da máxima de que os fins justificam os meios, pois no ideal de purificar a raça ariana elegeram-se como verdadeiros inimigos do Estado, não somente os judeus, mas os homossexuais, os deficientes e todos aqueles que supostamente eram contra o regime nazista. Como bem diz Günter Grass ${ }^{17}$, em sua obra de valor e beleza literários e de apropriada reflexão sobre esse passado da Alemanha nazista: "Auschwitz nos pertence, está gravado a ferro e fogo na nossa história"18. Esse passado de genocídio organizado e de monstruosidades não pode ser esquecido, passado a largo, muito menos significar um fim. Esse passado serve de lição e demostra como o homem é capaz de se autodestruir.

Concordamos com Manuel Monteiro Guedes Valente ${ }^{19}$, quando nos exorta sobre necessidade de repensar o Direito Penal, sob a ótica do garantismo ou do humanismo,

15 Sobre a atuação e função da Polícia, sobre os princípios regentes e a conduta policial na prossecução de suas atividades, conferir VALENTE, Manuel Monteiro Guedes - Teoria Geral do Direito Policial. 5. ${ }^{a}$ Ed. Coimbra: Almedina, 2017.

16 O Estado de Direito material social democrático assenta suas bases na dignidade da pessoa humana, sendo a dignidade "fundamento, razão, fim e limite dos operadores judiciários na materialização da política criminal e do direito penal material, processual e penitenciário". VALENTE, Manuel Monteiro Guedes - Direito Penal Fundamentos Político-Criminais. Lisboa: Manuel Monteiro Guedes Valente, 2017, p. 24.

17 GRASS, Günter - Escrever Depois de Auschwitz. 2. ${ }^{\mathrm{a}}$ Ed. , pp. 11-52.

18 GRASS, Günter - Escrever Depois de Auschwitz. 2. ${ }^{a}$ Ed., p. 51.

19 VALENTE, Manuel Monteiro Guedes - Direito Penal do Inimigo .... 3. a Ed. Portuguesa, pp. 147-148. 
GALILEU - e-ISSN 2184-1845 - Volume XXI . Issue Fascículo 1 - 15t July Julho - 31 th December Dezembro 2019 : pp. $192-196$

repensar a sua função de garantia que restringe o âmbito de sua incidência e confere uma visão mais crítica ao operador e aplicador do direito, nomeadamente quanto à cominação da sanção penal, que deve ser legítima e se dar sobre uma lesão ou perigo concreto ${ }^{20}$ de lesão.

Nesse contexto, impõe-se o questionamento sobre o conteúdo das estruturas sistemáticas e sobre a produção de leis e normas penais, porquanto leis e normas devem ser produzidas de acordo com critérios que justifiquem sua aplicação. Portanto, necessário impor resistência àquela norma que não recai sobre a ofensa a bem jurídico relevante, que viola a dignidade da pessoa humana, princípio tão caro ao Direito Penal garantista ou humanista.

\section{REFERÊNCIA BIBLIOGRÁFICA}

BECK, Ulrich - Sociedade de Risco Mundial - em Busca da Segurança Perdida. Lisboa: Edições 70, 2018. ISBN 978-972-40-7608-9.

COSTA, António Manuel de Almeida - 0 Funcionalismo Sistémico de N. Luhmann e os seus Reflexos no Universo Jurídico. Coimbra: Almedina, 2018. ISBN 978-972-40-7608-9.

GRASS, Günter - Escrever Depois de Auschwitz. 2. ${ }^{\text {a }}$ Ed. Português. Alfragide: Dom Quixote, 2008. ISBN 978-972-20-3651-1.

HESPANHA, António Manuel - O Caleidoscópio do Direito - O Direito e a Justiça nos dias e no mundo de hoje. 2. ${ }^{\text {a }}$ ed. Coimbra: Almedina, 2019. ISBN 978-972-40-3814-8.

JAKOBS, Günther e CANCIO MELIÁ, Manuel Derecho Penal del Enemigo. Tradução do alemão
Bürgerstrafrecht und Feindstrafrecht de Manuel Cancio Meliá. 2. ${ }^{a}$ Edição. Madrid: ThomsonCivitas, 2003. ISBN: 978-844-70-2063-0.

OTERO, PAULO - Direito Constitucional Português. Vol I: Identidade Constitucional. Coimbra: Almedina, 2017. ISBN 978-972-40-4149-0.

RAMOS, Calebe Brito; OLIVEIRA DE SOUZA, Rodrigo Lobato e ESTRELA, Thiago Aires - Direito Penal do Inimigo: para além da Constitucionalidade do Direito Penal (?).In: MANUEL MONTEIRO GUEDES VALENTE (Coord.). Os Desafios do Direito (Penal) do Século XXI. Lisboa: Legit Edições, 2018, pp.121-144. ISBN: 978-972-8973-51-3.

VALENTE, Manuel Monteiro Guedes - Direito Penal do Inimigo e o Terrorismo - O "Progresso ao Retrocesso". 3. ${ }^{\text {a }}$ Ed. Portuguesa. Coimbra: Almedina, 2019. ISBN 978-972-40-7962-2.

Direito Penal - Fundamentos PolíticoCriminais. Lisboa: Manuel Monteiro Guedes Valente, 2017. ISBN 978-972-99118-1-1. , Teoria Geral do Direito Policial. 5. ${ }^{\mathrm{a}}$ Ed. Coimbra: Almedina, 2017. ISBN 978-972-407017-9.

CONSTITUIÇÃO da República Portuguesa e legislação complementar/prefácio Pedro Trovão do Rosário; Introdução Henrique Dias da Silva. - Lisboa: Legit Edições, 2018. ISBN 978-972-8973-52-0.

20 Uma das críticas que se faz à teoria de G. Jakobs está na defesa que ele faz dos tipos penais de perigo abstrato, os quais prescindem da ocorrência do dano material efetivo a um bem jurídico. 